\title{
Effect of Panax Ginseng (GII5) Capsules versus Placebo on Acute Exacerbations in Patients with Moderate to Very Severe COPD: A Randomized Controlled Trial
}

This article was published in the following Dove Press journal:

International Journal of Chronic Obstructive Pulmonary Disease

\author{
Yuanbin Chen (iD ${ }^{1, *}$ \\ Lin $\operatorname{Lin} \mathbb{D}^{1, *}$ \\ Lei $\mathrm{Wu}^{\prime}$ \\ Yinji $X u^{\prime}$ \\ Johannah L Shergis $\mathbb{1}^{2}$ \\ Anthony L Zhang $\mathbb{D}^{2}$ \\ Zehuai Wen (D) \\ Christopher Worsnop ${ }^{3}$ \\ Cliff Da Costa ${ }^{4}$ \\ Frank Thien (iD) ${ }^{5}$ \\ Charlie C Xue ${ }^{1,2}$ \\ 'The Second Clinical College of \\ Guangzhou University of Chinese \\ Medicine, Guangdong Provincial Hospital \\ of Chinese Medicine and Guangdong \\ Provincial Academy of Chinese Medical \\ Sciences, Guangzhou, People's Republic \\ of China; ${ }^{2}$ School of Health and \\ Biomedical Sciences, RMIT University, \\ Bundoora, Victoria, Australia; ${ }^{3}$ Institute \\ of Breathing and Sleep, Austin Health, \\ Heidelberg, Victoria, Australia; ${ }^{4}$ School of \\ Science, RMIT University, Bundoora, \\ Victoria, Australia; ${ }^{5}$ Department of \\ Respiratory Medicine, Eastern Health, \\ Victoria, Australia, and Faculty of \\ Medicine, Nursing and Health Sciences, \\ Monash University, Melbourne, Victoria, \\ Australia
}

*These authors contributed equally to this work

Correspondence: Charlie C Xue School of Health and Biomedical Sciences, PO BOX 7I, Bundoora, Victoria 3083, Australia

Tel +6I 399257360

Fax +6I 399256539

Email charlie.xue@rmit.edu.au
Purpose: Herbal medicines are commonly used by people with chronic obstructive pulmonary disease (COPD) but high quality randomized controlled trials are limited. This study evaluated the therapeutic value of ginseng capsules in reducing acute exacerbations and improving the quality of life in people with COPD.

Patients and Methods: This randomized, double-blind and placebo-controlled trial assessed ginseng's effects on 200 patients with moderate to very severe COPD. Ginseng capsules (200 mg, twice per day) were compared to placebo over 24 weeks. Patients were followed up for a further 24 weeks after the treatment period. The primary outcome measure was acute COPD exacerbation rate over 12 months. Secondary outcome measures were health-related quality of life, including the St George's Respiratory Questionnaire (SGRQ), COPD Assessment Test (CAT) and the Short Form 36 Health Survey (SF-36). We also assessed lung function, walking distance and use of relief medication.

Results: Baseline characteristics were balanced between groups. The rate of COPD exacerbations was not statistically significant between groups after 1 year (62 participants in the ginseng group and 63 in the placebo group). Secondary outcome measures showed improvements after ginseng and placebo but results were not clinically significant. The incidence of adverse events in the two groups was similar and events were unrelated to the intervention. Conclusion: Compared with placebo, ginseng did not reduce the rate of acute COPD exacerbations over 12 months. It was safe and well tolerated by people with moderate to very severe COPD.

Keywords: COPD, ginseng, exacerbation, quality of life, randomized controlled trial

\section{Introduction}

Chronic obstructive pulmonary disease (COPD) is a common condition that affects about $12.16 \%$ of the population worldwide, with middle-aged and older adults more likely to be diagnosed. ${ }^{1}$ Global mortality studies indicate that COPD is the third leading cause of death worldwide, and the burden remains high despite some regions reporting fewer COPD-related deaths. ${ }^{2}$ In China, a large national crosssectional study tested the pulmonary function of 50,991 people, the prevalence of COPD was evaluated to be $13.7 \%$ for people aged 40 years or older. ${ }^{3}$ Cigarette smoking, occupational exposures and specific genetic syndromes are associated with the development of COPD. ${ }^{4}$ 
Long-term exposure to toxic substances and gases from cigarette smoke cause a complex cycle of inflammation and repair. ${ }^{5}$ In people with COPD, the normal response to stimulation of the airways by toxicants is amplified, resulting in pathological changes and abnormal inflammatory responses in the lungs. This amplified response leads to chronic airflow obstruction that is progressive and irreversible. It manifests as a productive cough (due to mucus hypersecretion) and breathlessness (due to hyperinflation secondary to airflow obstruction and lung parenchymal destruction). ${ }^{6}$ Invariably, COPD severely impacts the quality of life and needs regular treatment. Acute exacerbations of COPD present with increased dyspnoea and sputum purulence or volume or both, as well as fever and/or wheezing. Exacerbations are often caused by an upper airway infection. Preventing and treating exacerbations is central to the overall management of COPD, especially frequent exacerbations, which detrimentally affect health status and disease progression, and increase rates of hospitalization. ${ }^{7}$ COPD cannot be completely managed by a single intervention but requires a multidisciplinary approach. ${ }^{6,8}$ Although advanced multidisciplinary care is available, many people with COPD still have symptoms and exacerbations, hence there is a need to search for and test novel treatments.

Herbal medicines are complementary therapies that may provide new strategies for COPD treatment. A population-based cross-sectional study conducted in Taiwan indicated that the rate of prescribed herbal medicine for COPD was $51.97 \%$ in $2017 .{ }^{9}$ Evidence from Australia demonstrated that an approximate $20 \%$ of patients with moderate to severe COPD received herbal and natural preparations in 2004. ${ }^{10}$ Previous randomized controlled trials also indicate that herbal medicine such as Bufei Jipi granules and Bushen Yiqi granules may be effective for stable COPD. ${ }^{11,12}$ Panax ginseng C.A. Meyer, from the Araliaceae family, commonly known as "ginseng", is a popular herbal medicine which is commonly used all over the world. Ginseng is used to treat respiratory diseases, including COPD. ${ }^{13}$ The mechanism of ginseng relating to the treatment of COPD may include anti-inflammatory and antioxidant effects of its constituent compounds, the ginsenosides. ${ }^{14}$ Systematic reviews have indicated that ginseng is well tolerated. ${ }^{15,16}$ However, there are few high-quality randomized controlled trials of ginseng for the treatment of COPD. This study evaluated the therapeutic value and safety of standardized ginseng capsules in patients with moderate to very severe COPD.

\section{Materials and Methods}

\section{Study Design}

This randomized, double-blind, parallel-group, placebocontrolled clinical trial, randomized 200 participants with moderate to very severe COPD from three hospitals in China, including the Guangdong Provincial Hospital of Chinese Medicine, Guangzhou Charity Hospital and Guangdong Provincial Hospital of $\mathrm{Da}$ Xue Cheng. Participants were randomized in a 1:1 ratio to ginseng (400 mg daily) or matching placebo, using a computergenerated code. Participants, personnel and outcome assessors were blind to treatment allocation. The randomization numbers were concealed in opaque-sealed envelopes and study medication was coded. The study ran for 52 weeks: 4 weeks run in, to make sure participants did not have an acute COPD exacerbation; 24 weeks of treatment/placebo; and 24 weeks of follow up. All participants gave informed, written consent.

The study was registered (www.anzctr.org.au; ACTRN12613000382774) and a published protocol is available. ${ }^{17}$ The study was conducted according to the Declaration of Helsinki and ethical approval was obtained from the ethics committee of Guangdong Provincial Hospital of Chinese Medicine (Batch number B2012-49-01).

\section{Participants}

Participants were aged 40 years or older, had a diagnosis of moderate to very severe COPD, and were current-, exor non-smokers. Moderate to very severe COPD is defined by the Global Initiative for Chronic Obstructive Lung Disease (GOLD) Guidelines as $\mathrm{FEV}_{1} / \mathrm{FVC}$ less than 0.7 and $\mathrm{FEV}_{1}$ less than $80 \%$ predicted, confirmed by spirometry. ${ }^{18}$ When this study started in 2013, spirometry assessment was the primary classification for COPD, so we did not apply the ABCD assessment currently recommended in the GOLD guidelines. ${ }^{8}$

Participants were in the stable stage of COPD, that is, did not experience an acute infective exacerbation of COPD from at least 4 weeks prior to trial entry and, had not been hospitalized in the past 6 months with greater than three acute exacerbations. They also had to meet the Chinese medicine syndrome classification of Lung Qi deficiency with or without Spleen Qi or Kidney Qi deficiency, diagnosed by a registered Chinese medicine practitioner. Key exclusion criteria included participants with a history or current asthma; a history of chronic systemic infections or inflammatory conditions that required 
systematic corticosteroid treatment in the last 3 months; a diagnosis of alpha-1 antitrypsin deficiency; currently taking anticoagulants, antihyperglycemic, monamine oxidase inhibitor anti-depressants, immunosuppressive agents or immune-stimulants; undertaking pulmonary rehabilitation in the 3 months before the study started or intending to begin pulmonary rehabilitation during the study. Participants were also excluded if they had taken ginsengcontaining products in the 3 months before the study started or were allergic to ginseng.

\section{Interventions}

The ginseng $\left(\mathrm{G} 115^{\circledR}\right)$ capsules and placebo were manufactured following Good Manufacturing Practice (GMP) by Ginsana SA, Switzerland. Panax ginseng C.A Meyer standardized root extract was used for the intervention. Raw material was sourced from China and inspected by qualified experts at Ginsana for botanical and physical characteristics. Raw ginseng roots were processed and extracted using $96 \%$ ethanol, water $(40: 60 \mathrm{v} / \mathrm{v})$, producing a ratio of 5:1 herbal drug to extract ratio.

Chemical fingerprinting was also completed at the Ginsana laboratory. A retention sample is stored at Ginsana. The content of the final product includes $30-55 \%$ ginseng native extract, $2 \%$ silica colloidal anhydrous ( $\mathrm{Ph}$. Eur.) and 43-68\% lactose monohydrate (Ph. Eur.). One capsule contains $100 \mathrm{mg}$ of G115, standardized with $4 \mathrm{mg}$ of ginsenosides, the active/marker constituents. The ginseng was tested for aflatoxins, heavy metals and pesticide residue. G115 is the highest quality standardized ginseng product and has been evaluated in several laboratory studies and clinical trials. ${ }^{17,19}$

Participants were given ginseng or matching lactosebased placebo in $100 \mathrm{mg}$ gel-filled capsules to take orally in the morning and at night (200 mg, twice per day) for 24 weeks. We determined dose by referring to previous clinical trials and the manufacturer's recommendation. ${ }^{17,19}$

Participants were also given symptomatic relief medication (albuterol) to use as needed. Throughout the study, participants could continue their usual COPD medications, such as inhaled long-acting bronchodilators (eg tiotropium) alone or combined with corticosteroids (eg budesonide and formoterol fumarate), according to COPD guidelines. Participants taking other COPD medications, such as short-acting anticholinergics, theophylline and corticosteroids as monotherapy, were asked to discontinue the medication during the run-in period. If it was unsafe to discontinue or they refused, they were not eligible to join the study. Participants recorded their study medication and other medication in a take-home diary. We also asked them to return unused medication, so we could check it against their diary.

\section{Outcome Measures}

The primary endpoint was the rate of COPD exacerbations over 52 weeks. Secondary endpoints included the St George's Respiratory Questionnaire (SGRQ), COPD Assessment Test (CAT), Short Form 36 Health Survey (SF-36), exercise capacity using the 6-minute walking test (6MWT), $\mathrm{FEV}_{1}, \mathrm{FVC}$, and use of relief medication (albuterol) throughout the entire trial period.

We could not complete the planned data analysis of participants' use of COPD-specific medical resources, including medical practitioner and emergency department visits, due to low rates and incomplete reporting by the participants. We analyzed efficacy in an intention-to-treat population at the end of treatment (week 24) and in an available case population at the end of follow up (week 52).

We defined COPD exacerbations as an increase in one major symptom and more than one minor symptom, such as upper airway infection, unexpected fever or wheezing that lasted two or more days; or increases in two or more symptoms, such as dyspnoea and sputum purulence or volume or both. ${ }^{20}$ The participant's usual treating doctor managed exacerbations, and details were recorded in the case record form.

Questionnaires and spirometry were performed at baseline, beginning of treatment (4 weeks), mid-treatment (16 weeks), end of treatment (28 weeks), mid follow up (40 weeks) and end of follow up (52 weeks). The same person conducted assessments at each site. Site coordinators were experienced and trained in study implementation using standard procedures. Quality of life questionnaires was available in English and Chinese. Site data were merged for analysis. At each site, spirometry was performed using

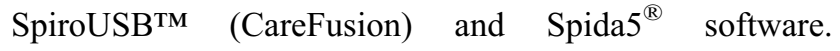
Spirometry was measured pre-bronchodilator and postbronchodilator after $400 \mu \mathrm{g}$ of inhaled albuterol.

Adverse events and serious adverse events were documented throughout the study. Participants recorded adverse events in their diaries, and researchers recorded any adverse events identified after contact with participants at their scheduled visits throughout the study. Blood samples were collected and full blood count and 
blood biochemistry for liver and kidney function were measured before and after treatment.

\section{Statistical Analysis}

An independent statistician, blinded to participant allocation, analyzed data using SPSS Version 24 (IBM Corp., Armonk, NY). The sample size (200 participants) was estimated based on the primary endpoint of an acute COPD exacerbation rate from a carbocisteine study, ${ }^{21}$ using an effect size estimate of a $30 \%$ difference between the groups, at an $80 \%$ power to detect a significant difference at the $5 \%$ level.

We assessed results for all endpoints within and between groups at baseline, end of treatment and end of follow up. In addition, we assessed the quality of life and lung function as change from baseline to end of treatment and end of follow up. Available cases were analyzed for the primary outcome, acute COPD exacerbation rate and use of relief medication. Intention-to-treat analysis was performed using imputation, with last observation carried forward up until the end of treatment for secondary outcomes, health-related quality of life, lung function and 6 -minute walking test. Due to the long period of follow up (24 weeks) when participants were not taking study interventions, and the unknown changes that could occur in patient symptoms, we dispensed with intention-to-treat in the follow-up period and analyzed available cases only.

Data are presented as changes from baseline via means, standard deviations and 95\% confidence intervals, except for exacerbations and use of relief medication data, which are presented as between-group differences at end of treatment and end of follow up using $t$-tests (paired $t$-tests) and chisquared tests.

Subgroup analysis was performed on all outcomes using various background variables, including location, smoking status, gender and age.

\section{Results}

Between April 2013 and November 2014, 200 participants were randomized (ginseng $n=100$ and placebo $n=100$ ) into this study. Of the 200 participants, 22 dropped out by week 52 (10 in the ginseng group and 12 in the placebo group). The reasons for dropping out are presented in Figure 1. Participant demographics and clinical characteristics were well matched across the groups at baseline (Table 1). The mean age was 68 years and most participants were men (185 [93\%]). Outcome results are shown in Table 2.

\section{Primary Endpoint Acute COPD Exacerbation Rate}

Over 52 weeks, 125 participants (62 in the ginseng group and 63 in the placebo group) experienced at least one COPD exacerbation. There was no difference between groups in terms of exacerbation rate measured as the number of exacerbations over 12 months (MD 0.08 [SE $0.18], 95 \% \mathrm{CI}-0.28$ to $0.45, p=0.69$, ginseng $n=113$ and placebo $n=118$ ). The time to first exacerbation in the ginseng group was on average 133.60 days after baseline (SD 97.69), and 140.14 days (SD 96.92) in the placebo group (MD 6.55 days [SE17.41], 95\% CI -27.91 to 41.0, $p=0.71$ ) (Table 2). There was also no difference in the number of days with an exacerbation between groups (MD 1.9 days [SE 1.75 ], 95\% CI -1.54 to $5.38, p=0.27$ ). The mean number of exacerbation events in the ginseng group was 1.16 (SD 1.29) and 1.24 (SD 1.17) in the placebo group. Subgroup analysis by smoking status (current smoker, ex-smoker or never smoked) and COPD severity (moderate, severe or very severe) showed similar results in the overall pool of participants. However, there was no difference between the ginseng and placebo groups.

\section{Secondary End-Points Health-Related Quality of Life}

There was no difference between groups in the SGRQ total score after treatment $(-1.11$ points [SE 1.49], 95\% CI -4.04 to $1.82, p=0.46)$ or follow up $(-1.99$ points [SE 1.56], 95\% CI -5.06 to $1.19, p=0.20$ ) (Table 2). The SGRQ total score reduced (indicating improvement) within the ginseng group after treatment (MD -2.07 points [SD 8.02], 95\% CI -3.66 to $-0.48, p=0.01$ ) but not follow up (MD -0.79 points [SD 9.73], 95\% CI -2.83 to 1.25 , $p=0.44$ ) (Table 3). The placebo group also showed improvement (reduction in SGRQ total score) after treatment (MD -2.98 points [SD 8.06], $95 \% \mathrm{CI}-4.58$ to -1.38 , $p<0.001)$ and follow up (MD -2.60 points [SD 8.86], 95\% $\mathrm{CI}-4.48$ to $-0.73, p=0.007)$. The number of participants achieving a 4-point difference after treatment was similar in each group, ginseng $n=41$ and placebo $n=44, p=0.67$. Subgroup analysis by COPD severity and smoking status showed similar improvements across all participants.

CAT scores were not significantly different between groups after treatment (MD -0.68 points [SE 0.70], 95\% $\mathrm{CI}-2.05$ to $0.69, p=0.33$ ) or follow up ( $\mathrm{MD}-0.84$ points [SE 0.77 ], $95 \% \mathrm{CI}-2.35$ to $0.67, p=0.27$ ). However, there 


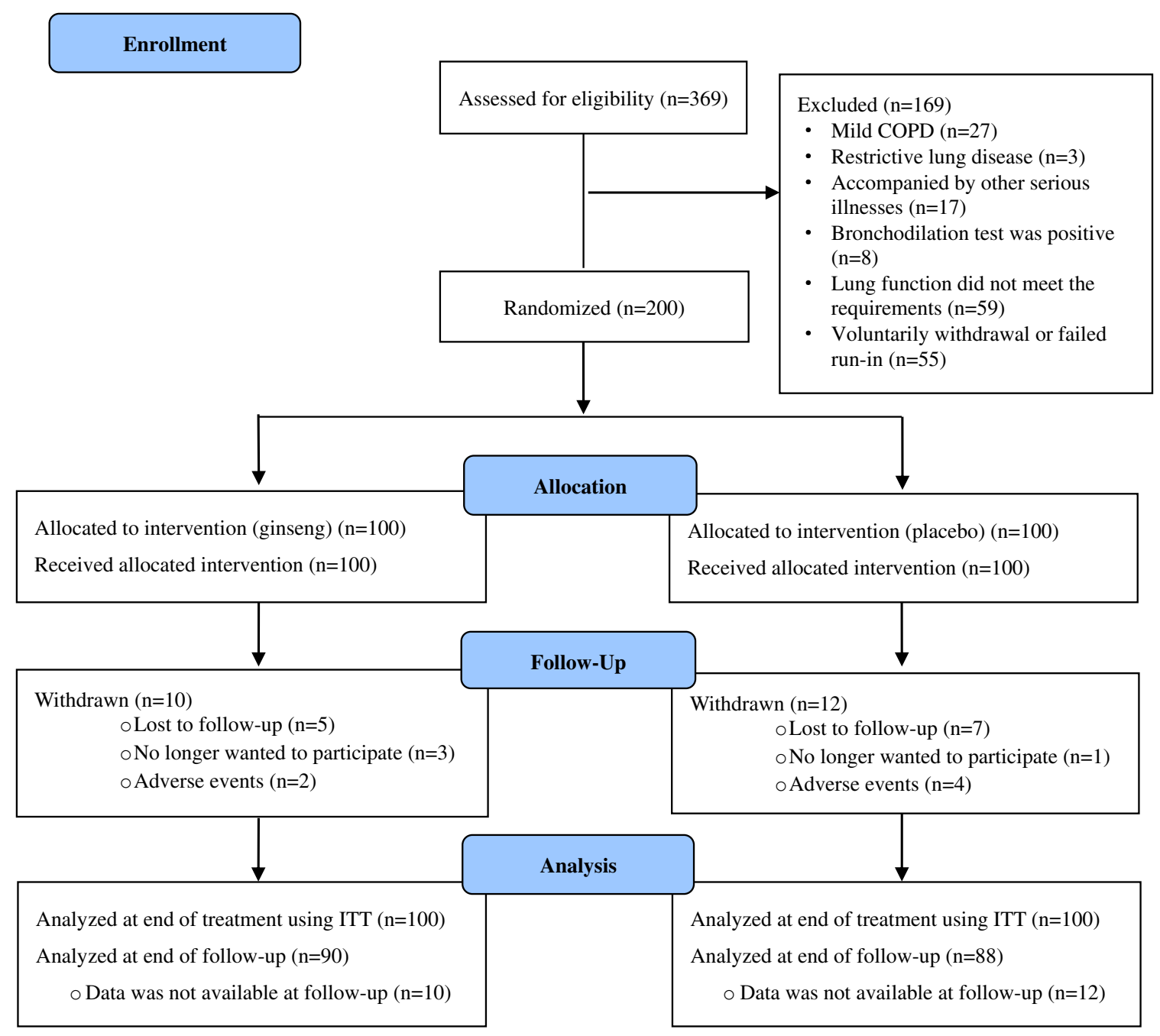

Figure I Flow diagram of study enrollment. Abbreviation: ITT, intention-to-treat.

were significant differences within the ginseng and placebo groups after treatment (reduction is score indicating improved symptoms) (MD -1.26 points [SD 4.59], 95\% CI -2.17 to $-0.35, p=0.007$ and $\mathrm{MD}-1.54$ points [SD 4.55], $95 \% \mathrm{CI}-2.44$ to $-0.64, \mathrm{p}=0.001$, respectively), but not follow up (MD -0.63 points [SD 5.30], $95 \% \mathrm{CI}-1.74$ to $0.48, p=0.28$ and $\mathrm{MD}-0.73$ points [SD 4.71 ], $95 \% \mathrm{CI}$ -1.17 to $0.27, p=0.15$, respectively).

The Short Form 36 Health Survey (SF-36) mental and physical scores were not significant between or within groups after treatment.

\section{Lung Function}

Significant differences in lung function were not observed between groups during treatment and at follow up (after treatment: $\mathrm{FEV}_{1}$ liters; MD 0.06 (SE 0.06), 95\% CI -0.06 to $0.17, p=0.36$, after follow-up MD 0.06 (SE 0.08 ), $95 \%$
CI -0.10 to $0.22, p=0.45$ ) (Table 2). Within the ginseng and placebo groups $\mathrm{FEV}_{1}$ liters did not improve after treatment or follow-up and overall lung function declined over 1 year (Table 3). Other lung function outcomes such as $\mathrm{FEV}_{1}$ percent and $\mathrm{FVC}$ also declined over 1 year.

\section{Use of Relief Medication}

The use of relief medication (albuterol) significantly reduced after ginseng and placebo treatments (MD 61.48 puffs [SD 119.32], $95 \%$ CI -85.16 to -37.80 , $p<0.001$ and MD -63.32 puffs [SD 118.35], 95\% CI -86.80 to $-39.35, p<0.001$, respectively). However, there was no significant difference between groups (Table 2).

\section{6-Minute Walking Test}

Results of the 6MWT were not statistically significant between groups after treatment or follow up (MD 
Table I Baseline Demographics and Clinical Characteristics

\begin{tabular}{|c|c|c|}
\hline Characteristic & $\begin{array}{l}\text { Ginseng } \\
(n=100)\end{array}$ & $\begin{array}{l}\text { Placebo } \\
(n=100)\end{array}$ \\
\hline $\begin{array}{l}\text { Age, year [mean (standard } \\
\text { deviation)] } \\
\text { Male, } \mathrm{n}(\%)\end{array}$ & $\begin{array}{l}69.01(7.57) \\
93(93)\end{array}$ & $\begin{array}{l}67.92(8.11) \\
92(92)\end{array}$ \\
\hline \multicolumn{3}{|l|}{ Smoking status } \\
\hline $\begin{array}{l}\text { - Current } \\
\text { - Former } \\
\text { - Non-smoker }\end{array}$ & $\begin{array}{l}27 \\
62 \\
11\end{array}$ & $\begin{array}{l}25 \\
59 \\
16\end{array}$ \\
\hline $\begin{array}{l}\text { Body Mass Index (BMI) [mean } \\
\text { (standard deviation)] }\end{array}$ & $23.98(5.31)$ & $21.11(3.78)$ \\
\hline $\mathrm{FEV}_{1}, \mathrm{~L}$ [mean (standard deviation)] & $1.21(0.4 \mathrm{I})$ & $1.27(0.48)$ \\
\hline $\begin{array}{l}\text { SGRQ total score [mean (standard } \\
\text { deviation)] }\end{array}$ & $31.85(11.6)$ & $32.27(12.6)$ \\
\hline \multicolumn{3}{|l|}{ COPD severity (GOLD Stage) } \\
\hline $\begin{array}{l}\text { - Moderate (Stage II) } \\
\text { - Severe (Stage III) } \\
\text { - Very severe (Stage IV) }\end{array}$ & $\begin{array}{l}41 \\
46 \\
13\end{array}$ & $\begin{array}{l}49 \\
38 \\
13\end{array}$ \\
\hline \multicolumn{3}{|l|}{ COPD medications } \\
\hline $\begin{array}{l}\text { - } \text { LABA } \\
\text { - } L A M A \\
\text { - } \text { LAMA/LABA } \\
\text { - ICS/LABA } \\
\text { - ICS/LABA/LAMA }\end{array}$ & $\begin{array}{l}0 \\
5 \\
0 \\
47 \\
7\end{array}$ & $\begin{array}{l}1 \\
3 \\
1 \\
44 \\
3\end{array}$ \\
\hline \multicolumn{3}{|l|}{ Chinese medicine diagnosis } \\
\hline $\begin{array}{l}\text { - Lung and spleen qi deficiency } \\
\text { - Lung, spleen, kidney qi deficiency } \\
\text { - Lung and Kidney deficiency }\end{array}$ & $\begin{array}{l}1 \\
59 \\
40\end{array}$ & $\begin{array}{l}1 \\
61 \\
38\end{array}$ \\
\hline
\end{tabular}

Note: Chi-squared and $t$-tests were used to analyze baseline data.

Abbreviations: $F E V_{1}$, forced expiratory volume in I s; GOLD, Global Initiative for Chronic Obstructive Lung Disease; ICS, inhaled corticosteroid; LABA, long-acting ß2-agonist; LAMA, long-acting muscarinic antagonist; SGRQ, St. George's Respiratory Questionnaire.

$-6.25 \mathrm{~m}$ [SE 13.33], 95\% CI -32.54 to $20.04, p=0.64$ and MD $0.85 \mathrm{~m}$ [SE 14.78], 95\% CI -28.32 to $30.03, p=0.95$, respectively). In addition, there were no significant differences within the ginseng or placebo groups (Table 3).

\section{Safety and Adverse Events}

One hundred and eleven participants (50 from the ginseng group and 61 from the placebo group) reported 161 adverse events. The most frequent events were common cold and acute laryngopharyngitis (Table 4). These events were not considered to be related to the ginseng intervention or placebo.
Table 2 Between-Group Differences at Weeks 28 and 52 for Various Outcomes

\begin{tabular}{|c|c|c|c|}
\hline Outcomes & $\begin{array}{l}\text { Mean } \\
\text { Difference } \\
\text { Between } \\
\text { Groups (SE) }\end{array}$ & $\begin{array}{l}95 \% \\
\text { Confidence } \\
\text { Interval }\end{array}$ & $\mathbf{p}$ \\
\hline \multicolumn{4}{|c|}{ End of treatment: Week 28} \\
\hline $\begin{array}{l}\text { SGRQ total score } \\
\text { CAT total score } \\
\text { SF-36 (mental score) } \\
\text { SF-36 (physical score) } \\
\text { FEV }_{1} \text {, liters } \\
\mathrm{FEV}_{1} \text { \% } \\
\text { FVC, liters } \\
\text { FVC, \% } \\
6 \mathrm{MWT} \text { meters } \\
\text { Use of relief medication, } \\
\text { puffs }\end{array}$ & $\begin{array}{l}-1.11(1.49) \\
-0.68(0.70) \\
0.30(0.80) \\
0.65(0.92) \\
0.06(0.06) \\
1.30(2.14) \\
0.05(0.09) \\
0.52(2.14) \\
-6.25(13.33) \\
2.89(21.58)\end{array}$ & $\begin{array}{l}-4.04 \text { to } 1.82 \\
-2.05 \text { to } 0.69 \\
-1.27 \text { to } 1.86 \\
-1.17 \text { to } 2.48 \\
-0.06 \text { to } 0.17 \\
-2.93 \text { to } 5.53 \\
-0.12 \text { to } 0.22 \\
-3.69 \text { to } 4.73 \\
-32.54 \text { to } 20.04 \\
-39.67 \text { to } 45.45\end{array}$ & $\begin{array}{l}0.46 \\
0.33 \\
0.71 \\
0.48 \\
0.36 \\
0.55 \\
0.56 \\
0.81 \\
0.64 \\
0.89\end{array}$ \\
\hline \multicolumn{4}{|l|}{ End of follow-up: Week 52} \\
\hline $\begin{array}{l}\text { Number of COPD } \\
\text { exacerbations }\end{array}$ & $0.08(0.18)$ & -0.28 to 0.45 & 0.69 \\
\hline $\begin{array}{l}\text { Time to first exacerbation, } \\
\text { days }\end{array}$ & $6.55(|7.4|)$ & -27.91 to 41.0 & 0.71 \\
\hline Days with an exacerbation & $1.9(1.75)$ & -1.54 to 5.38 & 0.27 \\
\hline SGRQ total score & $-1.99(1.56)$ & -5.06 to 1.09 & 0.20 \\
\hline CAT total score & $-0.84(0.77)$ & -2.35 to 0.67 & 0.27 \\
\hline $\mathrm{FEV}_{\mathrm{I}}$, liters & $0.06(0.08)$ & -0.10 to 0.22 & 0.45 \\
\hline $\mathrm{FEV}_{\mathrm{l}}, \%$ & $2.60(2.31)$ & -1.96 to 7.51 & 0.26 \\
\hline FVC, liters & $0.01(0.15)$ & -0.29 to 0.31 & 0.95 \\
\hline FVC, \% & $0.79(2.45)$ & -4.06 to 5.63 & 0.75 \\
\hline 6MWT meters & $0.85(14.78)$ & -28.32 to 30.03 & 0.95 \\
\hline $\begin{array}{l}\text { Use of relief medication, } \\
\text { puffs }\end{array}$ & $-11.54(20.68)$ & -52.36 to 29.28 & 0.58 \\
\hline
\end{tabular}

Notes: Lung function values are post-bronchodilator. Results are presented using intention-to-treat between baseline and end of treatment (week 28); intention-totreat was dispensed with at end of follow up (week 52). Two-sample t-tests were used for testing between-group differences.

Abbreviations: 6MWT, 6-minute Walking Test; CAT, COPD Assessment Test; COPD, chronic obstructive pulmonary disease; $\mathrm{FEV}_{1}$, forced expiratory volume in I s; FVC, forced vital capacity; SE, standard error; SGRQ, St Georges Respiratory Questionnaire; SF-36, short form 36 health survey.

Two serious adverse events were reported. One participant in the placebo group experienced an acute myocardial infarction and passed away. Another participant in the placebo group was diagnosed with a prostate tumor during the follow-up period, and he withdrew from the study. When the study ended, the participant was receiving ongoing care from their doctor. Both events were not considered to be related to the intervention.

Blood parameters, including full blood count and blood biochemistry for liver and renal function, were taken from each participant before and after treatment. After ginseng, 
Table 3 Within-Group Differences at Weeks 28 and 52 for Various Secondary Outcomes

\begin{tabular}{|c|c|c|c|}
\hline Outcome and Group & Baseline Mean (SD), 95\% Cl & $\begin{array}{l}\text { End of Treatment, Mean Change (SD), } 95 \% \\
\mathrm{Cl}\end{array}$ & $\begin{array}{l}\text { End of Follow-Up, Mean (SD), } 95 \% \\
\mathrm{Cl}\end{array}$ \\
\hline SGRQ total score: Ginseng & 30.19 (11.04), 28.00 to 32.38 & $-2.07(8.02),-3.66$ to $-0.48, p=0.01$ & $-0.79(9.73),-2.83$ to $1.25, p=0.44$ \\
\hline SGRQ total score: Placebo & 29.99 (II.45), 27.72 to 32.26 & $-2.98(8.06),-4.58$ to $-1.38, p<0.001$ & $-2.60(8.86),-4.48$ to $-0.73, p=0.007$ \\
\hline CAT total score: Ginseng & | $4.77(5.17), \mid 3.74$ to 15.80 & $-1.26(4.59),-2.17$ to $-0.35, p=0.007$ & $-0.63(5.30)-1.74$ to $0.48, p=0.28$ \\
\hline CAT total score: Placebo & $|4.37(5.32)| 3.3 \mid$, to 15.43 & $-1.54(4.55),-2.44$ to $-0.64, p=0.001$ & $-0.73(4.71),-1.17$ to $0.27, p=0.15$ \\
\hline SF-36 (mental score): Ginseng & $45.67(6.31), 44.42$ to 46.92 & $0.16(4.19),-0.67$ to $0.99, p=0.71$ & NA \\
\hline SF-36 (mental score): Placebo & 46.05 (5.77), 44.93 to 47.22 & $0.05(5.1 \mathrm{I}),-0.97$ to $1.06, p=0.92$ & NA \\
\hline SF-36 (physical score): Ginseng & 50.19 (7.06), 48.79 to 51.59 & $1.08(5.75),-0.06$ to $2.22, p=0.06$ & NA \\
\hline SF-36 (physical score): Placebo & $51.0(7.06), 49.60$ to 52.40 & $0.92(7.32),-0.53$ to $2.38, p=0.21$ & NA \\
\hline $\mathrm{FEV}_{\mathrm{l}}$, liters: Ginseng & $1.20(0.40), 1.12$ to 1.28 & $-0.04(0.13),-0.06$ to $-0.01, p=0.008$ & $-0.18(0.36)-0.25$ to $-0.11, p<0.001$ \\
\hline $\mathrm{FEV}_{\mathrm{I}}$, liters: Placebo & 1.29 (0.47), 1.20 to 1.39 & $-0.08(0.13),-0.10$ to $0.05, p<0.001$ & $-0.22(0.43),-0.30$ to $-0.13, p<0.001$ \\
\hline $\mathrm{FEV}_{\mathrm{l}}, \%$ : Ginseng & 47.17 (14.63), 44.27 to 50.07 & $-1.34(5.34),-2.40$ to $-0.28, p=0.014$ & $-2.10(6.01)-3.38$ to $-0.83, p=0.001$ \\
\hline $\mathrm{FEV}_{\mathrm{I}}$, \%: Placebo & 49.82 (16.28), 46.59 to 53.05 & $-2.69(4.97),-3.68$ to $-1.70, p<0.001$ & $-2.01(6.88),-3.49$ to $-0.54, p=0.008$ \\
\hline FVC, liters: Ginseng & $2.52(0.60), 2.40$ to 2.64 & $0.01(0.34),-0.06$ to $0.07, p=0.85$ & $-0.25(0.82)-0.41$ to $-0.08, p=0.003$ \\
\hline FVC, liters: Placebo & $2.60(0.62), 2.48$ to 2.72 & $-0.03(0.28),-0.08$ to $0.03, p=0.37$ & $-0.32(0.92),-0.50$ to $-1.4, p=0.001$ \\
\hline FVC, \%: Ginseng & 76.55 (14.33), 73.71 to 79.39 & $0.44(10.13),-1.57$ to $2.45, p=0.67$ & $1.35(11.54)-1.09$ to $3.80, p=0.28$ \\
\hline FVC, \%: Placebo & 78.06 (15.65), 74.96 to 81.16 & $-0.55(8.81),-2.30$ to $1.20, p=0.53$ & $1.30(10.3)-0.92$ to $3.50, p=0.25$ \\
\hline 6MWT meters: Ginseng & $\begin{array}{l}432.97(80.58), 416.98 \text { to } \\
448.96\end{array}$ & $3.17(52.21),-7.19$ to $13.53, p=0.55$ & $-3.34(61.90)-16.31$ to $9.62, p=0.61$ \\
\hline 6MWT meters: Placebo & $\begin{array}{l}419.53(87.63), 402.14 \text { to } \\
436.92\end{array}$ & $10.36(61.14),-1.77$ to $22.49, p=0.09$ & $6.19(68.04)-8.22$ to $20.61, p=0.40$ \\
\hline
\end{tabular}

Notes: Lung function values are post-bronchodilator. Results are presented using intention-to-treat between baseline and end of treatment; intention-to-treat was dispensed with at end of follow up. Paired t-tests were used for testing within-group difference.

Abbreviations: 6MWT, 6-minute Walking Test; CAT, COPD Assessment Test; Cl, confidence interval; FEV , forced expiratory volume in I s; FVC, forced vital capacity; NA, not applicable; SD, standard deviation; SGRQ, St Georges Respiratory Questionnaire; SF-36, Short Form 36 Health Survey.

12 participants showed slightly elevated white blood cell counts consistent with chronic inflammation. Two of these participants had elevated levels at baseline. Mild anemia was found in four other participants, but the results had no causal relationship with the ginseng intervention. Two of these participants' hemoglobin levels returned to normal after a second test and two had mild anemia at baseline. The participants' liver and kidney function tests were not clinically significant before or after treatment.

\section{Discussion}

Ginseng was similar to, but no better than, placebo for reducing exacerbations among participants with moderate to very severe COPD. Significant improvements were observed in the SGRQ and CAT total scores of participants in the ginseng and placebo groups after treatment. However, there was no statistically significant difference between the changes for each group. There was also no difference in SF-36, 6WMT, or lung function after treatment or follow up between or within the ginseng and placebo groups. Use of relief medication significantly reduced after ginseng and placebo treatments, but the reduction was similar for both groups. Overall, evidence showed that ginseng was no more beneficial than placebo for treating moderate to very severe COPD. The main results of this study are similar to our previous clinical trial of Panax ginseng for moderate COPD. ${ }^{22}$ In the previous study, ginseng was administered at a lower dose in people with more moderate COPD, and quality of life was the primary outcome.

Therefore, this is the first randomized, double-blind, placebo-controlled clinical trial evaluating the efficacy and safety of standardized Panax ginseng extract for moderate to very severe stable COPD.

The gold standard for clinical trials is a double-blind design, and placebo control is the key component in this design. A key issue with Chinese medicine clinical trials is placebo preparation and verification. Herbal medicines are often a combination of ingredients formulated into decoctions, granules or tablets, providing their own unique appearance and taste. ${ }^{23,24}$ Therefore, it is a challenge to prepare a placebo that matches the herbal medicines color, odor and taste. To tackle this issue, we chose an internationally recognized standardized ginseng extract, which was manufactured and certified under strict quality control procedures by a GMP-certified manufacturer.

In Traditional Chinese Medicine theory, ginseng is one of the few herbs used singularly. It is commonly used to 
Table 4 Adverse Events in the Ginseng and Placebo Groups

\begin{tabular}{|c|c|c|}
\hline Event Type & $\begin{array}{l}\text { Ginseng } \\
\text { (No. of Cases) }\end{array}$ & $\begin{array}{l}\text { Placebo } \\
\text { (No. of Cases) }\end{array}$ \\
\hline Common cold & 33 & 37 \\
\hline Acute laryngopharyngitis & 7 & 13 \\
\hline Acute gastroenteritis & 4 & 5 \\
\hline Eczema & 2 & 3 \\
\hline Leukocytosis & 3 & 0 \\
\hline Urinary tract infection & 0 & 3 \\
\hline Chest pain & 2 & 2 \\
\hline Gout & I & 2 \\
\hline Chronic gastritis & 2 & 1 \\
\hline Lumbar disc herniation & 2 & I \\
\hline Senile cataract & 2 & I \\
\hline Anemia & 2 & 0 \\
\hline Shingles & 0 & 2 \\
\hline Lacunar cerebral infarction & 2 & 0 \\
\hline Atrial flutter & 1 & 0 \\
\hline Acute myocardial infarction & 0 & $I^{*}$ \\
\hline Acute retention of urine & 0 & 1 \\
\hline Chest tightness & 0 & I \\
\hline Constipation & I & 0 \\
\hline Dizziness & 0 & I \\
\hline Epistaxis & I & 0 \\
\hline Gingivitis & 1 & 1 \\
\hline Gastro esophageal reflux & 0 & I \\
\hline Hemorrhoids & 0 & I \\
\hline Hypoglycemia & 0 & 1 \\
\hline Hypertension & I & 0 \\
\hline Haemoptysis & 1 & 0 \\
\hline Insomnia & 0 & 1 \\
\hline Increased creatinine & I & 0 \\
\hline Irritable bowel syndrome & I & 0 \\
\hline Loss of appetite & I & 0 \\
\hline Lower limbs swelling & I & 0 \\
\hline Prostatic hyperplasia & I & I \\
\hline Pleurisy & I & 0 \\
\hline Prostate tumor & 0 & $I^{*}$ \\
\hline Rib fracture & I & I \\
\hline Sexual dysfunction & I & 0 \\
\hline Seborrheic dermatitis & 0 & I \\
\hline Tinnitus & 0 & I \\
\hline Varicose veins of lower limbs & 0 & I \\
\hline
\end{tabular}

Note: *Serious adverse events.

treat the Chinese medicine syndrome classification of Lung Qi deficiency, improving symptoms of breathlessness. However, ginseng outcomes were not superior to placebo in this study. There are three main reasons why this may have happened.

1. Ginseng is commonly referred to as a "precious tonic" and highly recognized in China. This may have increased participants' confidence and led to an exaggerated placebo effect. It may also partly explain the SGRQ and CAT total scores improving in the placebo group after treatment.

2. COPD is a serious disease with complex mechanisms and continuous deterioration. In our study, a daily dose of $400 \mathrm{mg}$ may be insufficient for people with COPD. Compared with Chinese herbal medicine compounds with multiple ingredients, the therapeutic effect of ginseng appears to be relatively weak.

3. Ginseng was not a stand-alone treatment for COPD. Throughout the study, participants could continue their routine COPD medications according to COPD guidelines. In this case, the therapeutic advantages of ginseng may be difficult to decipher.

In terms of safety, our study showed that the nature and incidence of adverse events was similar across the ginseng and placebo groups. The most frequent events were common colds and acute laryngopharyngitis. Two serious adverse events were reported in the placebo group. However, they were not causally related to the study drug. These results demonstrate that ginseng is well tolerated in this group of people.

Our study had several limitations. First, all the participants were recruited in Guangdong Province potentially leading to population and geographical bias. Second, compared with large studies of COPD management, such as YUPINGFENG,${ }^{25}$ PANTHEON $^{26}$ and UPLIFT,${ }^{27}$ our sample size was relatively small. Third, the primary endpoint was the rate of acute exacerbations of COPD over 1 year; however, treatment duration was only 24 weeks. Moreover, we did not collect information on participants' COPD exacerbations before enrollment, and a history of exacerbations was not an inclusion criterion. This may have biased the results with the inclusion of infrequent exacerbators.

\section{Conclusions}

Ginseng was not more effective than placebo in the management of COPD. Therefore, our study does not support using ginseng as a complementary treatment for patients with COPD taking standard inhaled therapies. Future intervention studies should focus on early-stage COPD and ginseng as monotherapy.

\section{Data Sharing Statement}

Individual participant data collected during the trial are not available for sharing. However, the study protocol and 
statistical analysis plan are available on request following publication and ending 5 years after publication. Data will be shared following the submission of a methodologically sound proposal to the corresponding author and accessible at the time of request.

\section{Acknowledgments}

This study was supported by a National Health and Medical Research Council (NHMRC) Project (616609). The study was also funded by the Science and Technology Planning Project of Guangdong Province (2017A020213013), Science and Technology Research Project of Guangdong Provincial Hospital of Chinese Medicine (YN2018QL07 and YN2019ML03), and Zhongying Zhou Famous Doctors' Workshop of Guangdong Provincial Hospital of Chinese Medicine. Ginsana SA provided the Ginsana ${ }^{\circledR}$ capsules and placebo used in this study. The authors thank the patients for participating in this study. We also thank Michael De Lorenzo for his help with statistical analysis; and Louise Pobjoy for her support with proofreading the manuscript.

\section{Author Contributions}

All authors contributed to data analysis, drafting or revising the article, gave final approval of the version to be published, and agree to be accountable for all aspects of the work.

\section{Disclosure}

The authors report no conflicts of interest in this work.

\section{References}

1. Varmaghani M, Dehghani M, Heidari E, et al. Global prevalence of chronic obstructive pulmonary disease: systematic review and meta-analysis. East Mediterr Health J. 2019;25(1):47-57. doi:10.26719/emhj.18.014

2. Lozano R, Naghavi M, Foreman K, et al. Global and regional mortality from 235 causes of death for 20 age groups in 1990 and 2010: a systematic analysis for the Global Burden of Disease Study 2010. Lancet. 2012;380(9859):2095-2128. doi:10.1016/S0140-6736(12) 61728-0

3. Wang C, Xu J, Yang L, et al. Prevalence and risk factors of chronic obstructive pulmonary disease in China (the China Pulmonary Health [CPH] study): a national cross-sectional study. Lancet. 2018;391 (10131):1706-1717. doi:10.1016/S0140-6736(18)30841-9

4. Eisner MD, Anthonisen N, Coultas D, et al. An official American Thoracic Society public policy statement: novel risk factors and the global burden of chronic obstructive pulmonary disease. Am J Respir Crit Care Med. 2010;182(5):693-718. doi:10.1164/rccm.2008111757ST

5. Barnes PJ. Inflammatory mechanisms in patients with chronic obstructive pulmonary disease. J Allergy Clin Immunol. 2016;138(1):16-27. doi:10.1016/j.jaci.2016.05.011
6. MacNee W. ABC of chronic obstructive pulmonary disease: pathology, pathogenesis, and pathophysiology. BMJ. 2006;332 (7551):1202-1204. doi:10.1136/bmj.332.7551.1202

7. Wedzicha JA, Seemungal TA. COPD exacerbations: defining their cause and prevention. Lancet. 2007;370(9589):786-796. doi:10.1016/ S0140-6736(07)61382-8

8. Global Initiative for Chronic Obstructive Lung Disease. Global strategy for the diagnosis, management, and prevention of chronic obstructive pulmonary disease; 2019. Available from: https://gold copd.org. Accessed March 10, 2020.

9. Liao YN, Hu WL, Chen HJ, et al. the use of chinese herbal medicine in the treatment of chronic obstructive pulmonary disease (COPD). Am J Chin Med. 2017;45(2):225-238. doi:10.1142/S0192415X17500148

10. George J, Ioannides-Demos LL, Santamaria NM, et al. Use of complementary and alternative medicines by patients with chronic obstructive pulmonary disease. Med J Aust. 2004;181:248-251. doi:10.5694/j.1326-5377.2004.tb06262.x

11. Li SY, Li JS, Wang MH, et al. Effects of comprehensive therapy based on traditional Chinese medicine patterns in stable chronic obstructive pulmonary disease: a four-center, open-label, randomized, controlled study. BMC Complement Altern Med. 2012;12:197. doi:10.1186/1472-6882-12-197

12. Wang G, Liu B, Cao Y, et al. Effects of two Chinese herbal formulae for the treatment of moderate to severe stable chronic obstructive pulmonary disease: a multicenter, double-blind, randomized controlled trial. PLoS One. 2014;9(8):e103168. doi:10.1371/journal.pone.0103168

13. An X, Zhang AL, Yang AW, et al. Oral ginseng formulae for stable chronic obstructive pulmonary disease: a systematic review. Respir Med. 2011;105:165-176. doi:10.1016/j.rmed.2010.11.007

14. Shergis J, Di YM, Zhang AL, et al. Therapeutic potential of Panax ginseng and ginsenosides in the treatment of chronic obstructive pulmonary disease. Complement Ther Med. 2014;22:944-953. doi:10.1016/j.ctim.2014.08.006

15. Shergis JL, Zhang AL, Zhou W, et al. Panax ginseng in randomised controlled trials: a systematic review. Phytother Res. 2013;27:949-965. doi:10.1002/ptr.v27.7

16. Coon JT, Ernst E. Panax ginseng: a systematic review of adverse effects and drug interactions. Drug Saf. 2002;25:323-344. doi:10.2165/00002018-200225050-00003

17. Wu L, Zhang AL, Di YM, et al. Panax ginseng therapy for chronic obstructive pulmonary disease: a clinical trial protocol and pilot study. Chin Med. 2014;9:20. doi:10.1186/1749-8546-9-20

18. Global Initiative for Chronic Obstructive Lung Disease. Global Strategy for the Diagnosis, Management and Prevention of Chronic Obstructive Pulmonary Disease; 2012.

19. Scaglione F, Pannacci M, Petrini O. The standardised G115 Panax ginseng C.A. Meyer extract: a review of its properties and usage. Evid Based Integr Med. 2005;2(4):195-206. doi:10.2165/01197065200502040-00003

20. Anthonisen NR, Manfreda J, Warren CP, Hershfield ES, Harding GK, Nelson NA. Antibiotic therapy in exacerbations of chronic obstructive pulmonary disease. Ann Intern Med. 1987;106(2):196-204. doi:10.7326/0003-4819-106-2-196

21. Zheng JP, Kang J, Huang SG, et al. Effect of carbocisteine on acute exacerbation of chronic obstructive pulmonary disease (PEACE Study): a randomised placebo-controlled study. Lancet. 2008;371 (9629):2013-2018. doi:10.1016/S0140-6736(08)60869-7

22. Shergis JL, Thien F, Worsnop CJ, et al. 12-month randomised controlled trial of ginseng extract for moderate COPD. Thorax. 2019;74(6):1-7. doi:10.1136/thoraxjnl-2018-212665

23. Bian LQ, Li BS, Li ZH, et al. A preparation model of Chinese medicine decoction placebo. Chin J Integr Med. 2017;23 (8):631-634. doi:10.1007/s11655-016-2538-6

24. Huang QH, Xiao J, Sun YM, et al. Preparation and quality evaluation of traditional Chinese medicine compound placebo. Chin Med. 2015;56(15):1294-1297. 
25. Ma J, Zheng J, Zhong N, et al. Effects of YuPingFeng granules on acute exacerbations of COPD: a randomized, placebo-controlled study. Int J Chron Obstruct Pulmon Dis. 2018;13:3107-3114. doi: $10.2147 / \mathrm{COPD}$

26. Zheng JP, Wen FQ, Bai CX, et al. Twice daily N-acetylcysteine $600 \mathrm{mg}$ for exacerbations of chronic obstructive pulmonary disease (PANTHEON): a randomised, double-blind placebo-controlled trial. Lancet Respir Med. 2014;2(3):187-194. doi:10.1016/S2213-2600(13) 70286-8
27. Tashkin DP, Celli B, Senn S, et al. A 4-year trial of tiotropium in chronic obstructive pulmonary disease. $N$ Engl J Med. 2008;359 (15):1543-1554. doi:10.1056/NEJMoa0805800

\section{Publish your work in this journal}

The International Journal of COPD is an international, peer-reviewed journal of therapeutics and pharmacology focusing on concise rapid reporting of clinical studies and reviews in COPD. Special focus is given to the pathophysiological processes underlying the disease, intervention programs, patient focused education, and self management protocols. This journal is indexed on PubMed Central, MedLine and CAS. The manuscript management system is completely online and includes a very quick and fair peer-review system, which is all easy to use. Visit http://www.dovepress.com/testimonials.php to read real quotes from published authors. 